\title{
2021 and JPAP Achievements
}

\begin{abstract}
${ }^{1}$ Managing Editor, Journal of Professional \& Applied Psychology, Institute of Psychological Research, Multan, Pakistan.
\end{abstract}

Ahmad Bilal ${ }^{1}$

\section{Corresponding Author Email:}

meditor@iprpk.com

This is now the end of 2021 and It's a great time for the whole editorial team of Journal of Professional \& Applied Psychology (JPAP) that JPAP has now been recognized by Higher Education Commission (HEC) in $Y$ category and is now indexed in HJRS. This entails a huge part of dedication and commitment on part of editorial team. The authors and especially reviewers too deserve this credit as their contribution made this coordinated effort successful. It's a great achievement to be cherished by the whole family of JPAP to get HEC recognition. In fact, this huge achievement gave 2021 a flavor to cherish for times to come.

The JPAP has been indexed with J-Gate which is India's largest academic indexing agency. Besides, earlier, JPAP partnered with Crossref, ORCID, and Reviewer Credits. All the published articles can be viewed with the help of unique and functional DOIs. All authors can integrate their unique ORCID IDs with their papers. The esteemed reviewers of the JPAP can claim rewards for their review activity on Reviewer Credits, which is the growing hub for claiming rewards by the reviewers. Moreover, the JPAP offers discount in Article Publishing Charge (APC) to its esteemed reviewers.

The JPAP is now looking forward to be indexed in Scopus and other indexing agencies like PsycInfo. The process of JPAP indexing with Directory of Open Access Journals (DOAJ) and Committee on Publication Ethics (COPE) is already underway. With the trust of authors and assistance of our esteemed reviewers, we would achieve these milestones too.

The speed of publication matters significantly and is considered one of the quality indicators of an academic journal. Keeping in view the highest possible standards, the editorial team of JPAP strives to process a paper in possible short span of time while not compromising the quality of the review process.

JPAP is an open access journal and all published material is available under the creative commons license mentioned on each published paper. This becomes possible with the contribution of authors who bestow their trust in us and submit their scholarly work to our journal. The APC is used to cover publication related costs as JPAP solely depends on the contribution by the authors.

To keep the JPAP accelerating and exceling in the publishing field of psychological science, the editorial team of JPAP has now decided to publish it on quarterly basis so that our esteemed authors may get their papers online as soon as possible.

I hope, authors and reviewers would keep contributing for the improvement of JPAP by submitting and reviewing quality manuscripts respectively. I do hope that the year 2022 would bring other achievement milestones for JPAP.

Enjoy Reading!

This article is distributed under the terms of the Creative Commons Attribution Non Commercial 4.0 License (http://www.creativecommons.org/licenses/by-nc/4.0/) which permits non-Commercial use, reproduction and distribution of the work without further permission provided the original work is attributed as specified. 